\title{
Clinical profile of retinoblastoma presenting in a tertiary care hospital, eastern Nepal \\ P Lavaju ${ }^{1}$, BP Badhu ${ }^{1}$, S Shah ${ }^{1}$, SK Chaudhary ${ }^{1}$, P Upadhyaya ${ }^{2}$ \\ Department of Ophthalmology ${ }^{1}$, Department of Pathology ${ }^{2}$ \\ B.P. Koirala Institute of Health Sciences, Dharan, Nepal
}

\begin{abstract}
Background: Retinoblastoma is the commonest primary intraocular malignancy of childhood. Under-standing the different modes of presentation with timely intervention are associated with prognosis. Objective: To determine the clinical profile of retinoblastoma and its association with optic nerve infiltration by tumor. Methods: A retrospective analysis of the clinical records and histopathological reports of patients admitted with retinoblastoma in a tertiary heath care center, eastern Nepal (June 2009 to July 2012) was carried out. Results: A total of 27 patients (28 eyes) with retinoblastoma were studied. The mean age at presentation was $2.89 \pm 0.93$ years. The mean duration of symptoms to presentation was 3.35 month, ranged from 7 days to 2 years. Male to female ratio was 3:2. Thirty-three percent patients were Muslims. Twentyseven patients (96.3\%) had unilateral eye involvement. The commonest mode of presentation was leukocoria in 23 eyes (85.2\%) followed by redness 9 eyes (33.3\%), proptosis in 5 eyes (18.5\%) and phthisis bulbi in one eye (3.7\%). Histopathological reports of 26 eyes confirmed the diagnosis of retinoblastoma. One patient with distant metastases was referred to oncology center. Infiltration of the optic nerve by tumor cells was seen in five eyes (18.5\%); of which two cases had proptosis (p-0.166). At two years follow up, recurrence was seen in one patient with proptosis and optic nerve infiltration (p-0.136). Age at presentation was positively associated with recurrence of tumor ( $p-0.005)$. Conclusion: Leucokoria was the most common mode of presentation of retinoblastoma. Larger sample size with longer follow up is required to come to a definite association with optic nerve infiltration by tumor.
\end{abstract}

Keywords: Enucleation, leucokoria, proptosis, retinoblastoma, intraocular malignancy

\section{Address for correspondence}

Dr. Poonam Lavaju

Additional Professor

Department of Ophthalmology

B.P. Koirala Institue of Health Sciences, Dharan

Email: drpoonamlavaju@yahoo.com 


\section{Introduction}

Retinoblastoma is the most common intraocular malignancy during children. ${ }^{1}$ It could be unilateral $(2 / 3)$ or bilateral $(1 / 3){ }^{2}$ Incidence ranging from 1 in 15,000 to 1 in 18,000 live births \& bilateral in $1 / 3^{\text {rd }}$ of cases. The average age at diagnosis is 18 months, unilateral cases being diagnosed at around 24 months and bilateral cases before 12 months. ${ }^{3}$ Leukocoria, proptosis, squint, red eye and orbital cellulites have been reported as the frequent presentations of the disease. ${ }^{3}$ Proptosis is more common in developing countries. $^{4,5,6}$

The prognosis of retinoblastoma depends upon the mode of presentation, duration, site of involvement and histopathology stage and optic nerve involvement. Reported five year survival rate is seen $>90 \%$ in developed countries but is $<50 \%$ in developing countries. $^{7}$

Understanding the different modes of presentation may help in the early diagnosis and intervention. There is paucity of published data on various modes of clinical presentation of retinoblastoma from this area. So, the purpose of this study was to determine the clinical profile of retinoblastoma and its association with optic nerve cut end infiltration by tumor.
Methods_A retrospective analysis of clinical and histopathology reports of patients admitted with retinoblastoma in a tertiary health care hospital in eastern Nepal, BPKIHS was done over a period of three years, from June 2009 to July 2012. A detailed history was recorded in every case, including the family history. In all the patients detailed ocular and histopathology findings were recorded. The treatment options offered were enucleation, exenteration and in those with optic nerve stump infiltration and orbital extension were referred for chemotherapy and or radiotherapy.

Computed tomography scan or magnetic resonance imaging of the orbit and brain were recorded where ever possible. The diagnosis of retinoblastoma was made clinically, confirmed by histopathology findings and computed axial tomography scanning of orbits and brain.

Statistical analysis was done using SPSS version 11.5. Mean, standard deviation, 95\% confidence interval $(\mathrm{Cl})$ and percentage were calculated for descriptive varibles. P-values were calculated for the association of clinical presentation and histopathological findings. $P$ $<0.05$ was regarded as significant. 


\section{Results}

There were 27 patients admitted with a diagnosis of retinoblastoma during the study period. Of these, 26 patients had unilateral involvement and in only one patient, both the eyes were involved (total $=28$ eyes). There was a slight male preponderance, with a male: female ratio of 1.45:1. Eighteen were Hindus and 9 Muslims. History of consanguineous marriage was present in all the families from the Muslim community. There was no history of similar disease in their family.
The mean duration of symptoms to presentation to the hospital was 3.95 months with median 2.50 months.

Latency period from onset of symptoms to diagnosis was 7 days to 2 years.

The age of the patients ranged from three months to eight years with mean \pm SD; $2.89 \pm$ 0.93 . Majority of the patients were in the age group <5 years of age (85\%); most in between 3-5 years of age $(48 \%, n-13)$ [Table 1]. The mean age for male was $2.72 \pm 2.08$ and for female $3.09 \pm 1.81$ years.

Table 1: Distribution of age and gender in patients with retinoblastoma

\begin{tabular}{|l|l|l|l|l|}
\hline \multicolumn{1}{|c|}{ Age $($ years $)$} & \multicolumn{1}{|c|}{ Male } & \multicolumn{1}{c|}{ Female } & \multicolumn{1}{c|}{ Total } & \multicolumn{1}{c|}{ Percentage } \\
\hline$<5$ year & 14 & 9 & 23 & 85.1 \\
\hline$>5$ year & 2 & 2 & 4 & 14.9 \\
\hline Total & 16 & 11 & 27 & 100 \\
\hline
\end{tabular}

Leucokoria was the most common mode of presentation in 23 eyes (85\%) followed by secondary glaucoma in 9 eyes (33.3\%), proptosis in 5 eyes (18.5\%) and phthisis one eye $(3.7 \%)$ (Table 2$)$. One or more signs were present in the same patient. All the patients at the time of presentation had either leucokoria or congestion of the eye.
The mean age of the children with proptosis was $4 \pm 2.34$ years and without proptosis were $2.62 \pm 1.81$ years $(p-0.821)$. The mean duration of presentation to hospital in patients with proptosis was $3.03 \pm 3.58$ months and without proptosis was $7.97 \pm 10.14$ ( $p-0.001)$. Funduscopy examination of both the parents was normal. 
Table 2: Distribution of clinical presentation

\begin{tabular}{|l|l|l|}
\hline \multicolumn{1}{|c|}{ Clinical presentation } & \multicolumn{1}{|c|}{ No of patients $(\mathrm{n}=27)$} & \multicolumn{1}{c|}{ Percentage } \\
\hline Leucokoria & 23 & 85.2 \\
\hline Glaucoma & 9 & 33.3 \\
\hline Proptosis & 5 & 18.5 \\
\hline Phthsis bulbi & 1 & 3.7 \\
\hline
\end{tabular}

Twenty three patients underwent enucleation and two with orbital extension, exenteration was done. Examination of the fellow eye was done under general anesthesia. One patient with orbital and intracranial extension denied intervention and was referred for chemotherapy and radiotherapy. Histopathological reports of 25 eyes confirmed the diagnosis of retinoblastoma.
Infiltration of the cut end of the optic nerve by tumor cells was noted in 5 eyes (19.2\%), out of which two had proptosis at the time of presentation ( $p-0.155)$.In two patients sclera involvement was seen. Patients with extraocular involvement and optic nerve infiltration were referred for chemotherapy and /or radiotherapy.

Table 3: Association of histopathology findings with the duration of symptoms and age at presentation

\begin{tabular}{|c|c|c|c|}
\hline & \multicolumn{2}{|c|}{ Histopathology findings } & \\
\hline & $\begin{array}{c}\text { Optic nerve cut end } \\
\text { free }\end{array}$ & $\begin{array}{c}\text { Optic nerve cut end } \\
\text { infiltration }\end{array}$ & \multirow[t]{2}{*}{${ }^{*} p$-value } \\
\hline $\mathrm{N}(\%)$ & $21(80.76 \%)$ & $5(19.23 \%)$ & \\
\hline $\begin{array}{l}\text { Mean duration of } \\
\text { presentation (months) }\end{array}$ & $3.32 \pm 4.90$ & $7.32 \pm 7.42$ & $\begin{array}{l}0.07 \text { (OR 24, } 95 \% \\
\mathrm{Cl}-9.557-1.55)\end{array}$ \\
\hline $\begin{array}{l}\text { Mean duration of age } \\
\text { (years ) }\end{array}$ & $2.6 \pm 1.85$ & $4.2 \pm 2.16$ & $\begin{array}{l}0.991 \text { (OR 24, 95\% } \\
\mathrm{Cl}-3.56-0.36)\end{array}$ \\
\hline
\end{tabular}

*T test

We did not find any association between optic nerve cut end infiltration by tumor cells with mean age and mean duration of the disease (Table 3). 
Similarly there was no association seen between optic nerve cut end infiltration with sex (p-0.65), leucokoria ( $p-0.51)$, proptosis ( $p-0.155)$ and secondary glaucoma ( $p-0.502)$. At two years follow up, only one patient with proptosis and optic nerve end infiltration had recurrence of tumor (p-0.136). Age at presentation showed positive association with recurrence of tumor $(p-0.005)$ but failed to see association with sex, duration of disease and leucokoria, with $p$ value $0.593,0.137$ and 0.852 respectively.

\section{Discussion}

Retinoblastoma is the most common primary intraocular malignancy in children. In the previously reported literature the common age of presentation of retinoblastoma ranged from 15 months to 24 months. ${ }^{2}$ In the present study, the mean age of the patient was $2.9 \pm$ 0.93 years (3months to 7 years) which his similar to data reported from Nepal by Badhu et al and Saiju et al where, the mean age was $3.04 \pm 1.8$ years $^{6}$ and 3.1 years $^{9}$.

There was slight preponderance of male with male to female ratio1.45:1, which is consistent with other studies reported in the literature. ${ }^{6,10}$ Twenty six (96\%) patients had unilateral involvement and only one had bilateral involvement. Previous studies have found the distribution of bilateral to total cases of retinoblastoma to be around 9.3- 40
\%. ${ }^{6,9-11}$ The mean duration of presentation in this study was 3.95 months with latency up to 2 years. Delayed presentation up to $41 \pm 14$ months has been reported in the literature. ${ }^{5,6,11}$

The most common clinical presentation was leucokoria in 23 eyes (85.2 \%), followed by glaucoma (33.3\%) and proptosis in 5 eyes (18.5\%). In a study done by Saiju et al, out of $80 \%$ cases of leucokoria, eleven patients $(36.6 \%)$ presented with leukocoria as their only symptom. ${ }^{9}$ Similarly in the other studies too, leucokoria was the most common presenting symptom. ${ }^{12,13}$ These results contrast with previous studies of retinoblastoma in Nepal in which proptosis was the primary mode of presentation $(40 \%)^{5}$ and fungating mass was a more common mode of presentation. ${ }^{9}$ These changes could be because of increase in awareness of people to seek for medical advice. Abdu et al in their study, $46 \%$ patient presented with fungating orbital mass, leucokoira $22 \%$, proptosis $19 \%$, hyphaema $7 \%$, hypopyon $2 \%$, squint $2 \%$ and buphthalmos $2 \% .{ }^{14}$

Phthisis bulb, though a rare mode of presentation, has been reported in the literature. ${ }^{15,16}$ In this study, only one patient presented with phthisis bulbi. This highlights about the need of detail evaluation of children presenting with phthisis bulbi to rule out retinoblastoma. 
Optic nerve cut end infiltration by tumor cells was detected in $19.2 \%$ which was less than reported in previous studies from same hospital $(38 \%){ }^{6}$ This change in pattern depicts increase in health awareness of patient and accessibility of health care. We did not find significant association between recurrence of the tumor with infiltration of tumor at the cut end of the optic nerve, proptosis and age of the patient (Table 6). This could be because of small sample size and shorter follow up peroid. Unlike this, previous study conducted in the same hospital by Badhu et al found an association between proptosis and orbital extension with optic nerve infiltration ( $R R$ 21.33, $p<0.001$ ). Similar to our study, Shields et $\mathrm{al}^{18}$ also did not find an association of age with optic nerve invasion.

Most of the patients (97.2\%) underwent enucleation and exenteration in $4.9 \%$. This rate is consistent with previous studies by Badhu et $\mathrm{al}^{6}$ and Saiju et $\mathrm{al}^{9}$ where the rate of enucleation was $58 \%, 90 \%$ and exenteration $41.8 \%, 6.7 \%$ respectively. At a minimum of 2-years of follow up, recurrence was seen in only one patient, who had proptosis and optic nerve cut end infiltration by tumor cells. Early detection of retinoblastoma, when leucokoria is the only symptom present, is associated with a more favorable prognosis. ${ }^{2}$
Reddy et al in their study, with minimum follow up of two years found that $94 \%$ were well and alive. ${ }^{19}$

In a study conducted by Badhu et al, patients with proptosis and orbital extension died within one year. Now, the decrease number of cases with proptosis and increased proportion of reported cases with leukocoria in the same hospital may reflect improvement in public awareness of retinoblastoma and the timely seeking for medical advice. Increasing awareness and health accessibility can prevent morbidity.

\section{Conclusion}

Leucokoria was the most common clinical presentation. We recommend study with longer follow, to help eliciting an association of histopathology findings with clinical presentation of retinoblastoma and its morbidity.

\section{References}

1. Pizzo PA, Poplack DG. Principals and practice of pediatric oncology, $4^{\text {th }} \mathrm{ed}$. Lippincott-Raven: Philadelphia 2001:828-846

2. Abramson $\mathrm{DH}$, Ellsworth RM, Retinoblastoma: survival, age at detection and comparison 1914-1958, 
1958-1983. J of peadiatric Ophthalmol Strabismus. 1985;22(6):246-250.

3. Shields JA, Shields CL. Intraocular tumors - A text and Atlas. Philadelphia, PA, USA, WB Saunders Company, 1992.

4. Owoeye JF, Afolayan EA, AdemolaPopoola DS. Retinoblastoma-a clinicopathological study in Ilorin, Nigeria. 2006;13 (1-2):117-123.

5. Goddard AG, Kingston JE, Hungerford JL. Delay in diagnosis of retinoblastoma: risk factors and treatment outcome. 1999;83 (12):13201323.

6. Badhu BP, Sah SP, Thakur SK, Dulal S, Kumar S, Sood A, Das H, Sah RP. Clinical presentation of retinoblastoma in Eastern Nepal. Clinical and Experimental Ophthalmology 2005;33: 386-389.

7. MacCarthy A, Draper GJ, SteliarovaFoucher $E$, Kingston JE. Retinoblastoma incidence and survival in European children (1978-1997). Eur J Cancer. 2006 Sep; 42(13):20922102.

8. Sastre X, Chantada GL, Doz F, Wilson MW, de Davila MTG, RodríguezGalindo C, et al. Proceedings of the consensus meetings from the International Retinoblastoma Staging
Working Group on the pathology guidelines for the examination of enucleated eyes and evaluation of prognostic risk factors in retinoblastoma. Arch Pathol Lab Med. 2009;133: 1199-202.

9. Saiju R, Thakur J, Karmacharya PC, Shah DN (2006). Retinoblastoma in Nepal: a clinical profile of 30 cases. Nepal Med Coll J; 8(3):171-175.

10. Amozorrutia-Alegría V, Bravo-Ortiz JC, Vázquez-Viveros $\mathrm{J}$, et al.Epidemiological characteristics of retinoblastoma in children attending the Mexican Social Security Institute in Mexico City, 1990- 94. Paediatr Perinat Epidemiol; 200216(4): 370-374.

11. Kaimbo WK, Mvitu MM, Missotten L. Presenting signs of retinoblastoma in Congolese patients. Bull Soc Belge Ophtalmol 2002; 283: 37-41.

12. Aung L, Chan $\mathrm{YH}$, Yeoh EJ, Tan PL, Quah TC. Retinoblastoma: a recent experience at the National University Hospital, Singapore. Ann Acad Med Singapore. 2009;38: 693-698.

13. Chen $\mathrm{YH}$, Lin HY, Hsu WM, Lee SM, Cheng CY. Retinoblastoma in Taiwan: incidence and survival characteristics from 1979 to 2003. Eye (London) 2010; 24; 318-322. 
14. Abdu $\mathrm{L}$ and Malami S. 19. Chawla B, Sharma S, Sen S, Azad R, Clinicopathological pattern and management of retinoblastoma in Kano, Nigeria. Annals of African Medicine. 2011; 10: 214-219.

15. Jain I S, Singh K. Retinoblastoma in phthisis bulbi. Indian $\mathrm{J}$ Ophthalmol 1968; 16 (2):76-78.

16. Kashyap S, Meel R, Puskar N, Sen S, Bakhshi $S$ et al. Phthsis bulbi in retinoblastoma. Clinical and Experimental Ophthalmology 2011; 39(2):105-111.

17. Zhao J, Li S, Shi J and Wang N. Clinical presentation and group classification of newly diagnosed intraocular retinoblastoma in China. British Journal of Ophthalmology 2011; 95: 1372-75.

18. Shields CL, Shields JA, Baez K, Cater $J R$, De Potter P. Optic nerve invasion of retinoblastoma. Metastatic potential and clinical risk factors. Cancer 1994; 73: 692-698. 